\title{
RESEARCH
}

Open Access

\section{The effect of socioeconomic position in the experience of disability among people with mental disorders: findings from the World Mental Health Survey Initiative Portugal}

Ana Antunes ${ }^{1,2^{*}}$ (D), Diana Frasquilho ${ }^{1,2}$, Sofia Azeredo-Lopes ${ }^{2}$, Manuela Silva ${ }^{1,2}$, Graça Cardoso ${ }^{1,2}$ and José Miguel Caldas-de-Almeida ${ }^{1,2}$

\begin{abstract}
Background: Mental disorders are a major cause of disability with impacts on daily functioning and quality of life, which has been associated with socioeconomic disadvantage. The present study aims to assess how socioeconomic position is related to the disability reported by people with mental disorders, using data from the World Mental Health Survey (WMHS) Initiative Portugal.

Methods: Using data from the Portuguese Mental Health Survey, a nationally representative cross-sectional study $(n=3849)$, several logistic regression models with interaction terms were performed to evaluate the effect of different indicators of socioeconomic position on the disability reported by people with any mental disorder (any 12-month mood or anxiety disorder). Odds ratios were estimated at the specific values of the main effects and interaction terms between the presence of any mental disorder and education, employment status, self-perceived financial deprivation and subjective social status.

Results: The prevalence rate of any mood or anxiety disorder was $21.0 \%(n=788)$, among which $14.7 \%(n=115)$ reported disability. The results show that among people with any 12-month mental disorder, those in the employment category of "retired or others" had two times higher odds of reporting disability (OR=2.19; 95\%Cl: 1 . 06-4.48) when compared to participants categorized as "working". Likewise, individuals with financial deprivation had two times higher odds of reporting disability when compared to those non-financially deprived $(\mathrm{OR}=2.36$; 95\%Cl: 1.31-4.24). The odds ratios obtained for the specific years of education evaluated were not statistically significant but seem to suggest an educational gradient.

Conclusions: The findings of this study indicate that the disability reported by people with mental disorders varies according to socioeconomic position and draw attention to the need to develop policies to address these inequalities.
\end{abstract}

Keywords: Mental disorders, Disability, Socioeconomic position, Social inequalities

\footnotetext{
* Correspondence: ana.antunes@nms.unl.pt

${ }^{1}$ Chronic Diseases Research Center (CEDOC), Nova Medical School, Nova University of Lisbon, Rua do Instituto Bacteriológico, n5, 1150-082 Lisbon, Portugal

${ }^{2}$ Nova Medical School, Nova University of Lisbon, Campo Mártires da Pátria 130, 1169-056 Lisbon, Portugal
}

(c) The Author(s). 2018 Open Access This article is distributed under the terms of the Creative Commons Attribution 4.0 International License (http://creativecommons.org/licenses/by/4.0/), which permits unrestricted use, distribution, and reproduction in any medium, provided you give appropriate credit to the original author(s) and the source, provide a link to the Creative Commons license, and indicate if changes were made. The Creative Commons Public Domain Dedication waiver (http://creativecommons.org/publicdomain/zero/1.0/) applies to the data made available in this article, unless otherwise stated. 


\section{Background}

Mental disorders are highly prevalent and represent a major cause of disability worldwide [1,2]. Disability has been defined as functioning restrictions or activity limitations in multiple dimensions of life that results from the interaction between health determinants and contextual factors [3-6]. Mental disorders represent a challenge to individuals' quality of life, daily functioning and work performance, possibly contributing to reduction of income and standards of living [7-14]. The labour force participation rate of people with mental disorders has been found to be lower when compared to the rest of the population due to higher unemployment rates, sickness absence and early retirement [15-19]. Consequently, studies have shown productivity loss as a main contributor to the economic burden of these disorders $[8,13,20,21]$.

Under a public health perspective, alongside prevention efforts and access to adequate healthcare, it is important to evaluate which factors may contribute to increased levels of disability among people with mental disorders. For instance, studies have suggested a higher risk of disability due to mental disorders among those socioeconomically more disadvantaged [22-26]. Specifically, educational gradients in sickness absence and early retirement due to mental disorders have been found [25, 26], as well as socioeconomic inequalities in onset, duration and recurrence of work related disability due to depression and other mental disorders [22-26]. Moreover, the risk of exclusion from the labour market among people with mental disorders is likely to aggravate existing social inequalities [27].

The identification of socioeconomic inequalities in the experience of disability among people with mental disorders may represent an opportunity to develop interventions to reduce its impact on well-being and associated personal and economic costs [27, 28]. However, the use of different indicators, particularly those assessing disability, limits comparisons across settings. This also represents an important public health challenge in Portugal since the results from the World Mental Health Survey (WMHS) Initiative (2008/9) have shown a high prevalence rate of 12 -month mental disorders (22.9\%), associated with substantial societal costs, particularly relevant in relation to other countries $[8,29]$. Studies using days out of role as an indicator of disability, corresponding to the number of days in the last 30 that individuals were unable to work or carry out their normal activities due to health-related problems, have found mental disorders to be responsible for $20.2 \%$ of days out of role in Portugal, in comparison to $16.0 \%$ among high-income WMHS countries, assessed through its population attributable risk proportion $[8,13]$.
This study aimed to examine the role of socioeconomic position in the experience of disability among people with mental disorders. It was hypothesized that the odds of reporting disability vary according to socioeconomic position, affecting disproportionately those more disadvantaged. Socioeconomic position is a concept widely used in epidemiological research and refers to social and economic factors that contribute for an individuals' position within society [30]. Indicators of socioeconomic position may not be inter-changeable [31] and be differently associated with health outcomes across the life course [30]. Therefore, the indicators included in this study, namely education, employment status, self-reported financial deprivation and subjective social status, were evaluated independently, integrating both the assessment of objective and subjective aspects of socioeconomic position.

Portugal is among the most unequal European countries and an absence of research and policy efforts to effectively tackle health inequalities have been reported [32]. The results of this study may contribute to a better understanding on the effect of social inequalities in the experience of disability among people with mental disorders, for which current knowledge is still scarce, providing valuable insights for policy making.

\section{Methods}

\section{Design and study sample}

Data was collected through a National Mental Health Survey, carried out in Portugal between 2008 and 2009, within the WMHS Initiative, designed to evaluate the prevalence, severity, distribution and consequences of mental disorders through the collection of cross-nationally representative epidemiological data using standardized methods worldwide [2, 33].

A cross-sectional study based on a stratified multistage clustered area probability household sample was administered to a nationally representative sample of respondents. The participants were Portuguese-speaking adults aged 18 years old or above, residing in permanent private dwellings in the country's mainland. Informed consent was obtained before the interviews and the procedures were approved by the Ethics Committee of the Nova Medical School, Nova University of Lisbon [33].

The survey was conducted by trained lay interviewers on a face-to-face setting, using computer-assisted personal interview (CAPI). The response rate was 57.3\%, similar to the surveys in Belgium, France, Germany, and the Netherlands. No substitutions from the initially selected households were allowed when the originally sampled household resident could not be interviewed [33].

In order to reduce respondent burden, internal subsampling was used by dividing the questionnaire in two parts. Part I included the core diagnostic assessment of 
mental disorders. All respondents meeting the criteria for any mental disorders also completed Part II, together with a probability sample of $25 \%$ randomly selected participants who did not meet criteria for any mental disorder. Part II included the assessment of predictors and consequences of mental disorders and use of services [33].

The total number of interviews was 3849. Both modules (Part I and Part II) were administered to 2060 participants. Part I data was weighted to adjust for differential probabilities of selection, between and within households, non-response bias and discrepancies between the sample and the socio-demographic and geographic data distribution from the census population. Part II was additionally weighted to adjust for the differential sampling of Part I participants into Part II. Further details regarding the study design and fieldwork procedures can be found elsewhere [33].

\section{Measurements}

\section{2-month mental disorders}

The presence of any mood and anxiety disorder in the 12 months before the interview were evaluated with the version 3.0 of the WHO Composite International Diagnostic Interview (CIDI), a fully-structured diagnostic interview [34]. A clinical reappraisal study compared the diagnoses obtained by the CIDI 3.0 with those generated by the clinician-administered non-patient edition of the Structured Clinical Interview for DSM-IV (SCID) and showed good concordance between the CIDI 3.0 and SCID estimates for 12-month mental disorders [35]. The diagnoses of mental disorders, assessed using the criteria of the American Psychiatric Association's Diagnostic and Statistical Manual Disorders Fourth Edition (DSM-IV) [36], were the following: anxiety disorders (panic disorder, generalized anxiety disorder, social phobia, specific phobia, agoraphobia without panic disorder, post-traumatic stress disorder, obsessive-compulsive disorder and adult separation anxiety) and mood disorders (major depressive disorder, dysthymia and bipolar disorder including bipolar I and II). A dichotomous variable was created to indicate the presence or absence of any mental disorder in the past year.

\section{Disability (WMHS WHODAS-II)}

Disability was assessed with the modified version of the World Health Organization Disability Assessment Schedule (WHODAS-II) for the WMHS Initiative (WMHS WHODAS-II). This instrument is based on the International Classification of Functioning, Disability and Health Framework [4] and was applied to the participants of the Part II sample. The internal consistency and validity of the WMHS WHODAS-II has been demonstrated [37]. Difficulties in the 30 days prior to the assessment were evaluated in the following life domains:
1- Understanding and communication (cognitive domain);

2- Moving and getting around (mobility domain);

3- Personal hygiene, dressing, eating and ability to live alone (self-care domain);

4- Interaction with other individuals (social interaction domain);

5- Difficulties carrying out work or normal activities (time out of role domain).

The specific questions included in each domain can be found elsewhere [37]. The domains scores range from 0 to 100 , with higher scores meaning greater disability. A global disability score aggregating all domains scores was obtained. Given the distributional properties of the instrument, this score was dichotomized at the 90th percentile to indicate the presence or absence of substantial disability [37].

\section{Indicators of socioeconomic position}

Education was assessed through the number of years of education reported by the participants, as a continuous variable. Specific years were selected to report the data by choosing the main milestones of the Portuguese educational system (0 years- no education; 4 years- primary education; 9 years- preparatory education; 12 - secondary education; 17 - university).

Regarding employment status, the participants were classified in the following categories: 1 - working at the time of interview or students; 2- unemployed and 3- retired and others (e.g. homemakers and those under sickness absence).

Self-reported financial deprivation was assessed by asking the participants "would you say you have/ your family living here has: 1- more money than you need; 2just enough for your needs, or 3- not enough to meet your needs". A dichotomous variable was created considering the participants with or without perceived financial deprivation (more than enough or enough money for needs vs not enough money, respectively).

Subjective social status was measured with the MacArthur scale, which has shown good reliability and validity [38]. The scale consists in a stepladder with rungs numbered from 1 to 10, with the highest value at the top. Participants were asked to consider the ladder as representing the people in Portugal, where those at the top of the ladder would be better off, in contrast to those at the bottom, who have the least money, least education and the least respected jobs or no job. A dichotomous variable characterized the scores into two categories: low or low-mid scores (1-5) and high mid and high scores (6-10) with the first indicating a low subjective social status [38]. 


\section{Covariates}

All models were adjusted for age and gender. The presence of any physical disorder was also considered as a covariate since the comorbidity between physical and mental disorders has been associated with higher levels of disability [39]. Physical disorders were assessed with a chronic disorders checklist that has shown good concordance with medical records $[40,41]$.

\section{Data analysis}

Means, standard deviations (SD), frequencies and percentages were used to describe the population under study. A multivariate logistic regression model was performed to assess the association between disability and presence of any 12-month mental disorder. Multiple logistic regression models included interaction terms to enable the interpretation of the interaction effect of each indicator of socioeconomic position with the presence of any 12-month mental disorder on disability. To be in accordance with the objectives of the study, the odds ratios (OR) were estimated and interpreted at specific levels of the main effects and interaction terms considering the results among individuals with any 12-month mental disorder. Statistical significance was assessed by $95 \%$ confidence intervals (95\% CI). The standard errors of the odds ratio estimates, used to obtain the confidence intervals, employed values from the variance-covariance matrix of the corresponding model fits [42, 43]. All estimates were weighted according to the characteristics of the study, as previously explained. Data analysis was conducted using Statistical Package for Social Sciences (SPSS) version 22.0 and $\mathrm{R}$ version 3.4.2.

\section{Results}

Table 1 presents the demographic, socioeconomic and clinical characteristics of the sample. Of the 3849

Table 1 Descriptive statistics of the demographic, socioeconomic and clinical characteristics of the WMHS Portugal sample and subsample of participants with any mental disorder

\begin{tabular}{|c|c|c|c|c|}
\hline \multirow[b]{2}{*}{ Demographic and socioeconomic characteristics } & \multirow{2}{*}{$\begin{array}{l}\text { WMHS Portugal total sample }(n=3849) \\
\mathrm{n}\end{array}$} & \multicolumn{3}{|c|}{ Participants with any mental disorder $(n=788)$} \\
\hline & & $\%$ & $\mathrm{n}$ & $\%$ \\
\hline \multicolumn{5}{|l|}{ Gender $^{a}$} \\
\hline Female & 2217 & 51.6 & 596 & 70.1 \\
\hline Male & 1632 & 48.4 & 192 & 29.9 \\
\hline \multicolumn{5}{|l|}{ Employment status $^{\mathrm{b}}$} \\
\hline Working & 1362 & 65.1 & 430 & 69.6 \\
\hline Unemployed & 172 & 6.8 & 40 & 8.3 \\
\hline Retired and others & 526 & 28.1 & 133 & 22.2 \\
\hline \multicolumn{5}{|l|}{ Financial deprivation ${ }^{\mathrm{b}}$} \\
\hline No & 1311 & 66.8 & 410 & 58.9 \\
\hline Yes & 732 & 33.2 & 303 & 41.1 \\
\hline \multicolumn{5}{|l|}{ Subjective social status $^{\mathrm{a}}$} \\
\hline High & 2463 & 65.1 & 482 & 62.4 \\
\hline \multirow[t]{2}{*}{ Low } & 1344 & 34.9 & 300 & 37.6 \\
\hline & Mean & SD & Mean & SD \\
\hline $\mathrm{Age}^{\mathrm{a}}$ & 46.38 & 16.88 & 42.82 & 15.19 \\
\hline Education $^{a}$ & 8.76 & 4.79 & 9.50 & 4.64 \\
\hline Clinical characteristics & $\mathrm{n}$ & $\%$ & $\mathrm{n}$ & $\%$ \\
\hline \multicolumn{5}{|l|}{ 12-month mental disorders ${ }^{b}$} \\
\hline Any mental disorder & 788 & 21.0 & - & - \\
\hline \multicolumn{5}{|l|}{ Physical disorders ${ }^{\mathrm{b}}$} \\
\hline Any physical disorder & 1513 & 68.7 & 588 & 82.2 \\
\hline \multicolumn{5}{|l|}{ Disability $^{\mathrm{b}}$} \\
\hline Presence of substantial disability & 212 & 8.6 & 115 & 14.7 \\
\hline
\end{tabular}

Descriptive statistics of the study sample and sub-sample with any 12-month mental disorder SD standard deviation, WMHS World Mental Health Survey

$\mathrm{n}$ : unweighted; \%, mean, SD: weighted

a Part I weight

b Part II weight 
participants interviewed, 51.6\% $(n=2217)$ were women. The mean age of the participants was $46.38(\mathrm{SD}=16.88)$ and the mean years of education were $8.76(\mathrm{SD}=4.79)$. The majority of the participants were working at the time of interview $(65.1 \% ; n=1362)$. Financial deprivation was reported by $33.2 \%(n=732)$ of the participants and $34.9 \%(n=1344)$ perceive themselves to have a low social status in comparison to others in society. The prevalence rate of any 12-month mental disorder was $21.0 \%$ $(n=788)$ and the prevalence of disability was $8.6 \%(n=$ 212). Among people with any mental disorder, higher levels of unemployment $(8.3 \% ; n=40)$, financial deprivation $(41.1 \% ; n=303)$ and low subjective social status $(37.6 \% ; n=300)$ were found. Moreover, $14.7 \%$ ( $n$ $=115$ ) of these participants reported disability.

Table 2 shows the association between the presence of any mental disorder and disability. After adjusting for age, gender and presence of any physical disorder, people with any mental disorder were almost 3 times more likely to report disability when compared to those without any mental disorder ( $\mathrm{OR}=2.82$; 95\% CI: $1.95-4.09)$.

Table 3 presents the odds ratios of the interaction effects between the presence of any mental disorder and each category of the indicators of socioeconomic position on disability. The results indicate that, after adjusting for age, gender and presence of any physical disorder, the association between disability and presence of any mental disorder varies significantly according to the category of the indicators evaluated, namely employment status (being "retired or others") and perceived financial deprivation (being financially deprived). Among people with any mental disorder, those classified as "retired or others" were found to be 2.19 times more likely to report disability when compared to those in the working group ( $\mathrm{OR}=2.19$; 95\%CI: 1.06-4.48). Likewise, individuals financially deprived were 2.36 times more likely to report disability when compared to those who did not report this situation $(\mathrm{OR}=2.36$; 95\%CI: $1.31-4.24)$. The same pattern was found regarding unemployment and low subjective social status, although not statistically significant. The results obtained in the specific years of education selected to report data were not statistically significant as well. However, among participants with any mental disorder, those with lower levels of education

Table 2 Odds ratio (OR) and respective 95\% confidence interval $(95 \% \mathrm{Cl})$ of the association between the presence of any $12-$ month mental disorder and disability

\begin{tabular}{ll}
\hline Any 12-month mental disorder & OR $(95 \% \mathrm{Cl})$ \\
\hline Yes & $2.82(1.95-4.09)^{* * *}$ \\
No & Ref. \\
\hline
\end{tabular}

Part II weight

Model adjusted for age, gender and presence of any physical disorder *** $p<0.001$
Table 3 Odds ratios (OR) and respective 95\% confidence intervals $(95 \% \mathrm{Cl})$ for disability, considering participants with any 12-month mental disorder, based on the interaction terms with education, employment status, self-perceived financial deprivation and subjective social status

\begin{tabular}{lc}
\hline Interaction Effects & OR $(95 \% \mathrm{Cl})$ \\
\hline Presence of any mental disorder * Education & \\
No education & $1.81(0.57-5.82)$ \\
4 years & $1.58(0.65-3.84)$ \\
9 years & $1.32(0.76-2.29)$ \\
12 years & $1.19(0.85-1.68)$ \\
17 years & Ref. \\
Presence of any mental disorder * Employment status \\
Working or students & Ref. \\
Unemployed & $1.87(0.78-4.53)$ \\
Retired or others & $2.19(1.06-4.48) *$ \\
Presence of any mental disorder * Financial deprivation \\
No & Ref. \\
Yes & $2.36(1.31-4.24) *$ \\
Presence of any mental disorder * Subjective social status \\
High & Ref. \\
Low & $1.45(0.81,2.60)$ \\
\hline
\end{tabular}

Odds ratio estimates obtained from four multivariate logistic regression models

All models adjusted for gender, age and presence of any physical disorder Part II weight

${ }^{*} p<0.05$

appeared to be more likely to report disability when compared to the highest level of education and a gradient was suggest by the results (e.g. no education: $\mathrm{OR}=$ 1.81, 95\%CI: $0.57-5.82$; 4 years of education: $\mathrm{OR}=1.58$, 95\%CI: $0.65-3.84$; and 12 years of education: $\mathrm{OR}=1.19$, 95\%CI: 0.85-1.68).

\section{Discussion}

The objective of this study was to evaluate the effect of socioeconomic position on the disability experienced by people with mental disorders. As hypothesised, the findings suggest that the likelihood of reporting disability varies according to socioeconomic position, in particular employment status and perceived financial deprivation. Participants with any mental disorders in the category of "retired or others" and who perceived themselves as financially deprived had two times higher odds of reporting disability, when compared to those working and not financially deprived, respectively. Moreover, despite not reaching statistical significance, an education gradient seems to be suggested by the results, given that among people with any mental disorder, those with the lowest years of education were almost two times more likely to 
report disability, with the odds decreasing alongside the number of years of education.

The results are in line with previous research. Studies have shown a lower labour force participation of individuals with mental health problems due to early retirement and sickness absence, among other factors [15, 18, 19, 27]. It is important to highlight that in this study early retirement was not evaluated separately but the association was adjusted for age. The findings on perceived financial deprivation are aligned with research suggesting higher levels of economic disadvantage among individuals with disability due to mental disorders $[17,18,27]$. Regarding education, despite the absence of statistical significance, the results are in line with studies that found an education gradient in the risk of early retirement and long term sickness absence due to mental health problems $[25,26]$. It has been suggested that individuals with lower socioeconomic position are more likely to have demanding occupations, both physically and psychosocially, or may not have the same opportunities to accommodate their ill-health on their task requirements and working conditions [25]. This may be particularly relevant within the context of the Portuguese welfare system, characterized by providing the smallest public expenditure per capita in social protection in Western Europe, alongside other Southern European countries [44].

The findings of this study should be interpreted within several limitations. The cross-sectional design limits causal inference, namely to understand if the differences in the experience of disability among people with mental disorders according to socioeconomic position are related to factors existing before the onset of disability, to the onset itself or its duration over time [45]. However, two main pathways may operate co-currently: Among people with mental disorders, those with lower socioeconomic position may be more likely to experience disability. Low socioeconomic position has been associated with higher prevalence of mental disorders and disability, due to risk factors such as low educational level, unemployment, precarious working conditions and lower standards of living [18, 27, 28]. Also, the experience of disability among individuals with mental disorders may further aggravate socioeconomic inequalities. The onset and duration of mental disorders and disability have been associated with more adverse economic outcomes such as job loss, reduced income and healthcare expenditure $[17,27,45]$.

Furthermore, similar to other research in this area, disability was evaluated in the previous month, whereas mental disorders are 12-month based. For episodic conditions, the past month disability may not include the time period of the disorder, while using a 12-month diagnosis allows the inclusion of remitted disorders that may have residual adverse effects on disability $[10,13]$. Besides, the changes made to reduce respondent burden in the WHODAS-II in the WMHS, such as the use of filter questions, impaired the measurement properties with scores having highly skewed distributions with low mean scores and large proportions of zero scores [37]. To address this issue, the cut-off for defining substantial disability (percentile 90th) has been recommended. However, this procedure may mask cross-national differences and caution is needed when comparing the results obtained in this study with those from other countries [37]. Another possible limitation is the use of a broad category of any mental disorder, which does not consider differences that may occur in the experience of disability associated with specific conditions. Finally, this study fails to account for the recent macroeconomic changes in Portugal, one of the European countries most affected by the global financial crisis [46]. Mental health and well-being are likely to deteriorate more immediately and severely than other health outcomes during periods of economic recession [47], contributing to wider health and social inequalities that may not be represented in the results. This scenario may be further aggravated by the absence of effective policies to address social and health inequalities in Portugal [32]. In spite of these limitations, to our knowledge, this study was the first to assess the effect of socioeconomic position in the experience of disability among people with mental disorders in Portugal. Different indicators of socioeconomic position were used, complementing research in this area and drawing attention to the need to conduct longitudinal studies to ascertain the causal pathways involved in these associations. Furthermore, a nationally representative of the Portuguese population and robust instruments to access disability and mental disorders were used. The use of a multi-dimensional instrument to assess disability also represents a major strength of this study since most research uses indicators of productivity loss, which are difficult to compare and only partially assess the experience of disability.

\section{Conclusions}

In conclusion, despite the inability to ascertain the direction of causality, this study establishes the effect of specific social and economic factors in the experience of disability among people with mental disorders. The results highlight the need to further explore how socioeconomic position may contribute to differential patterns of vulnerability among this group and how disability may exacerbate existing social inequalities. Policies aiming to reduce the burden of disability associated to mental disorders may include the promotion of better access to mental health care services, alongside social inclusion and economic measures to protect the rights of people with mental disorders. 


\section{Abbreviations}

Cl: Confidence interval; CIDI: Composite International Diagnostic Interview; DSM-IV: American Psychiatric Association's Diagnostic and Statistical Manual Disorders Fourth Edition; OR: Odds ratio; SCID: Structured Clinical Interview for DSM-IV; SD: Standard deviation; WHODAS-II: World Health Organization Disability Assessment Schedule; WMHS: World Mental Health Survey

\section{Acknowledgements}

The authors wish to thank the World Mental Health Survey Initiative staff for their assistance with instrumentation, fieldwork, and data analysis. A complete list of funding support and publications can be found at: http:// www.hcp.med.harvard.edu/wmh.

\section{Funding}

AA receives a grant from the Portuguese Foundation for Science and Technology (FCT) [grant number PD/BD/105822/2014].

The Portuguese Mental Health Study was carried out by the Department of Mental Health, NOVA Medical School, NOVA University of Lisbon, with collaboration of the CESOP-Portuguese Catholic University and was funded by the Champalimaud Foundation, the Gulbenkian Foundation, the Foundation for Science and Technology (FCT) and the Ministry of Health. The Portuguese Mental Health Study was carried out in conjunction with the World Health Organization WMH Survey Initiative which is supported by the National Institute of Mental Health (NIMH; R01MH070884), the John D. and Catherine T. MacArthur Foundation, the Pfizer Foundation, the U.S. Public Health Service (R13-MH066849, R01-MH069864 and R01 DA016558), the Fogarty International Center (FIRCA R03-TW006481), the Pan American Health Organization, Eli Lilly and Company, Ortho- McNeil Pharmaceutical, GlaxoSmithKline and Bristol-Myers Squibb.

\section{Availability of data and materials}

The authors do not have permission to share data. Information on the World Mental Health Survey Initiative can be found at: http:// www.hcp.med.harvard.edu/wmh.

\section{Authors' contributions}

AA conceptualized the design and drafted the manuscript. DF contributed to the study conceptualization and manuscript revision. SAL contributed to data analysis and manuscript revision. MS and GC revised the manuscript. JMCA was the Principal Investigator of the World Mental Health Survey Initiative in Portugal, coordinated all activities and revised the manuscript. All authors have approved the text of the manuscript.

\section{Ethics approval and consent to participate}

All procedures performed in studies involving human participants were in accordance with the ethical standards of the Ethics Committee of the Nova Medical School, Nova University of Lisbon, and with the 1964 Helsinki declaration and its later amendments or comparable ethical standards. Informed consent was obtained from all individual participants included in the study.

\section{Consent for publication}

Not applicable.

\section{Competing interests}

The authors declare that they have no competing interests.

\section{Publisher's Note}

Springer Nature remains neutral with regard to jurisdictional claims in published maps and institutional affiliations.

\section{Received: 12 February 2018 Accepted: 10 July 2018} Published online: 07 August 2018

\section{References}

1. Whiteford HA, Degenhardt L, Rehm J, Baxter AJ, Ferrari AJ, Erskine HE, et al. Global burden of disease attributable to mental and substance use disorders: findings from the global burden of disease study 2010. Lancet. 2013;382:1575-86
2. Kessler RC, Aguilar-Gaxiola S, Alonso J, Chatterji S, Lee S, Ormel J, et al. The global burden of mental disorders: an update from the WHO world mental health (WMH) surveys. Epidemiol Psichiatr Soc. 2011;18:23-33.

3. Porta M. A dictionary of epidemiology. 6th ed. Oxford: Oxford University Press; 2014.

4. World Health Organization. Measuring Health and Disability: Manual for WHO disability assessment schedule WHODAS 2.0. Geneva: World Health Organization; 2010.

5. Leonardi M, Bickenbach J, Ustun TB, Kostanjsek N, Chatterji S. The definition of disability: what is in a name? Lancet. 2006;368:1219-21.

6. World Health Organization. World report on disability. Geneva: World Health Organization; 2011.

7. McDaid D, Curran C, Knapp M. Promoting mental well-being in the workplace: a European policy perspective. Int Rev Psychiatry. 2005;17:365-73.

8. Cardoso G, Xavier M, Vilagut G, Petukhova M, Alonso J, Kessler RC, Caldasde-Almeida JM. Days out of role due to common physical and mental conditions in Portugal: results from the WHO world mental health survey. BJPsych Open. 2017;3(1):15-21.

9. Barbaglia G, Adroher ND, Vilagut G, Bruffaerts R, Bunting B, Caldas de Almeida JM, et al. Health conditions and role limitation in three European regions: a public-health perspective. Gac Sanit. 2016;31:2-10.

10. De Graaf R, Tuithof M, Van Dorsselaer S, Ten Have M. Comparing the effects on work performance of mental and physical disorders. Soc Psychiatry Psychiatr Epidemiol. 2012;47(11):1873-83.

11. Bruffaerts R, Vilagut $G$, Demyttenaere $K$, Alonso J, Alhamzawi A, Andrade LH, et al. Role of common mental and physical disorders in partial disability around the world. Br J Psychiatry. 2012;200(6):454-61.

12. Karpov B, Joffe G, Aaltonen K, Suvisaari J, Baryshnikov I, Naatanen P, et al. Level of functioning, perceived work ability, and work status among psychiatric patients with major mental disorders. Eur Psychiatry. 2017:44:83-9.

13. Alonso J, Petukhova M, Vilagut G, Chatterji S, Heeringa S, Ustun TB, et al. Days out of role due to common physical and mental conditions: results from the WHO world mental health surveys. Mol Psychiatry. 2011;16:1234-46.

14. Lund C, Myer L, Stein DJ, Williams DR, Flisher AJ. Mental illness and lost income among adult south Africans. Soc Psychiatry Psychiatr Epidemiol. 2013:48:845-51.

15. Lahelma E, Pietiläinen O, Rahkonen O, Lallukka T. Common mental disorders and cause-specific disability retirement. Occup Environ Med. 2015;72:181-7.

16. Ekberg K, Wahlin C, Persson J, Bernfort L, Oberg B. Early and late return to work after sick leave: predictors in a cohort of sick-listed individuals with common mental disorders. J Occup Rehabil. 2015;25:627-37.

17. Schofield DJ, Shrestha RN, Percival R, Passey ME, Callander EJ, Kelly SJ. The personal and national costs of mental health conditions: impacts on income, taxes, government support payments due to lost labour force participation. BMC Psychiatry. 2011;11:72.

18. Cook JA. Employment barriers for persons with psychiatric disabilities: update of a report for the President's commission. Psychiatr Serv. 2006;57: 1391-405.

19. Knudsen AK, Harvey SB, Mykletun A, Overland S. Common mental disorders and long-term sickness absence in a general working population. The Hordaland health study. Acta Psychiatr Scand. 2013;127:287-97.

20. Gustavsson A, Svensson M, Jacobi F, Allgulander C, Alonso J, Beghi E, et al. Cost of disorders of the brain in Europe 2010. Eur Neuropsychopharmacol. 2011;21(10):718-79.

21. Bloom DE, Cafiero E, Jané-Llopis E, Abrahams-Gessel S, Bloom LR, Fathima S, et al. The global economic burden of noncommunicable diseases. Geneva: World Economic Forum; 2011.

22. Ervasti J, Vahtera J, Pentti J, Oksanen T, Ahola K, Kivimaki M, et al. Depression-related work disability: socioeconomic inequalities in onset, duration and recurrence. Plos One. 2013:8:4-11.

23. Virtanen M, Kawachi I, Oksanen T, Salo P, Tuisku K, Pulkki-Raback L, et al. Socio-economic differences in long-term psychiatric work disability: prospective cohort study of onset, recovery and recurrence. Occup Environ Med. 2011:68:791-8.

24. Melzer D, Fryers T, Jenkins R, Brugha T, McWilliams B. Social position and the common mental disorders with disability - estimates from the national psychiatric survey of Greart Britain. Soc Psychiatry Psychiatr Epidemiol. 2013;38:238-43.

25. Sumanen H, Rahkonen O, Pietilainen O, Lahelma E, Roos E, Lahti J. Educational differences in disability retirement among young employees in Helsinki, Finland. Eur J Pub Health. 2016;26:318-22. 
26. Sumanen H, Pietilainen O, Lahelma E, Rahkonen O. 10-year trends of educational differences in long sickness absence due to mental disorders. J Occup Health. 2017;59:352-5.

27. Emerson E, Madden R, Graham H, Llewellyn G, Hatton C, Robertson J. The health of disabled people and the social determinants of health. Public Health. 2011;125:145-7.

28. Allen J, Balfour R, Bell R, Marmot M. Social determinants of mental health. Int Rev Psychiatry. 2014;26:392-407.

29. Caldas-de-Almeida J, Xavier M. Estudo Epidemiológico Nacional de Saúde Mental - 1.o Relatório (National Mental Health Epidemiological Study - 1st Report). Lisbon: Nova Medical School; 2013.

30. Galobardes B, Shaw M, Lawlor DA, Lynch JW, Davey Smith G. Indicators of socioeconomic position (part 1). J Epidemiol Community Health. 2006;60:7-12.

31. Lahelma E. Pathways between socioeconomic determinants of health. J Epidemiol Community Heal. 2004;58:327-32.

32. Campos-Matos I, Russo G, Perelman J. Connecting the dots on health inequalities - a systematic review on the social determinants of health in Portugal. Int J Equity Health. 2016;15:26.

33. Xavier M, Baptista H, Mendes JM, Magalhaes P, Caldas-de-Almeida JM. Implementing the world mental health survey initiative in Portugal - rationale, design and fieldwork procedures. Int J Ment Health Syst. 2013;7:19.

34. Kessler RC, Ustun TB. The world mental health (WMH) survey initiative version of the World Health Organization (WHO) composite international diagnostic interview (CIDI). Int J Methods Psychiatr Res. 2004;13:93-121.

35. Haro JM, Arbabzadeh-Bouchez S, Brugha TS, de Girolamo G, Guyer ME, Jin $\mathrm{R}$, et al. Concordance of the composite international diagnostic interview version 3.0 (CIDI 3.0) with standardized clinical assessments in the WHO world mental health surveys. Int J Methods Psychiatr Res. 2006;15:167-80.

36. First MB, Gibbon M. The structured clinical interview for DSM-IV Axis I disorders (SCID-I) and the structured clinical interview for DSM-IV Axis II disorders (SCID-II). In: Hilsenroth M, Segal D, Hersen M, editors. Comprehensive handbook of psychological assessment, personality assessment. 1st ed. New York: Wiley; 2004. p. 134-43.

37. Von Korff M, Crane PK, Alonso J, Vilagut G, Angermeyer MC, Bruffaerts R, et al. Modified WHODAS-II provides valid measure of global disability but filter items increased skewness. J Clin Epidemiol. 2008;61:1132-43.

38. Scott KM, Al-Hamzawi AO, Andrade LH, Borges G, Caldas-de-Almeida JM Fiestas F, et al. Associations between subjective social status and DSM-IV disorders: results from the world mental health surveys. JAMA Psychiatry. 2014;71(12):1400-8.

39. Scott KM, Von Korff M, Alonso J, Angermeyer MC, Bromet E, Fayyad J, et al. Mental-physical co-morbidity and its relationship with disability: results from the world mental health surveys. Psychol Med. 2009;39:33-43.

40. Baker M, Stabile M, Deri C. What do self-reported, objective, measures of health measure? J Hum Resour. 2004;39(4):1067-93.

41. Knight M, Stewart-Brown S, Fletcher L. Estimating health needs: the impact of a checklist of conditions and quality of life measurement on health information derived from community surveys. J Public Health Med. 2001;23:179-86.

42. Hilbe JM. Logistic regression models. Boca Raton: Chapman \& Hall/CRC Press; 2009. p. 189-235.

43. Hosmer DW, Lemeshow S, Sturdivant RX. Applied logistic regression. New York: Wiley; 2013. p. 49-88.

44. Bambra C. Health inequalities and welfare state regimes: theoretical insights on a public health "puzzle.". J Epidemiol Community Health. 2011;65:740-5.

45. Jenkins SP, Rigg JA. Disability and disadvantage: selection, onset, and duration effects. J Soc Policy. 2004;33(3):479-501.

46. Legido-Quigley H, Karanikolos M, Hernandez-Plaza S, de Freitas C, Bernardo L, Padilla $B$, et al. Effects of the financial crisis and troika austerity measures on health and health care access in Portugal. Health Policy. 2016;120(7):833-9.

47. Marmot SM, Bloomer E, Goldblatt P. The role of social determinants in tackling health objectives in a context of economic crisis. Public Health Rev. 2013;35(9):1-24.

Ready to submit your research? Choose BMC and benefit from:

- fast, convenient online submission

- thorough peer review by experienced researchers in your field

- rapid publication on acceptance

- support for research data, including large and complex data types

- gold Open Access which fosters wider collaboration and increased citations

- maximum visibility for your research: over $100 \mathrm{M}$ website views per year

At BMC, research is always in progress.

Learn more biomedcentral.com/submissions 